\title{
Niche partitioning of picocyanobacterial lineages in the oligotrophic northwestern Pacific Ocean
}

\author{
Dong Han Choi ${ }^{1,2}$, Karen E. Selph ${ }^{3}$ and Jae Hoon Noh $^{1,4, *}$ \\ ${ }^{1}$ Biological Oceanography \& Marine Biology Division, Korea Institute of Ocean Science and Technology, Ansan 15627, Korea \\ ${ }^{2}$ Department of Marine Biotechnology, Korea University of Science and Technology, Daejeon 34113, Korea \\ ${ }^{3}$ Deparment of Oceanography, University of Hawaii, Honolulu, HI 96822, USA \\ ${ }^{4}$ Department of Marine Biology, Korea University of Science and Technology, Daejeon 34113, Korea
}

More than 20 and 10 clades / ecotypes of Synechococcus and Prochlorococcus, respectively, have been identified in various oceanic regions. However, their diversity has yet to be thoroughly studied in the northwest Pacific Ocean. Further, spatial distribution of Synechococcus clades in the oligotrophic oceans has been scarcely characterized. To elucidate picocyanobacterial lineage distribution in the northwest Pacific Ocean, 16S-23S internal transcribed spacer sequences of picocyanobacteria were sequenced by barcoded amplicon pyrosequencing method. Additional pyrosequencing library using a primer specific for the Synechococcus subcluster-5.1 was constructed to thoroughly understand Synechococcus diversity in the oligotrophic oceans. In warm pool area, Prochlorococcus was predominant and showed a distinct depthpartitioning between HLII and LL ecotypes. Despite low abundances, diverse Synechococcus clades appeared in the oligotrophic open ocean, showing both vertical and horizontal niche partitioning. Clade II was the predominant Synechococcus clade, especially in upper euphotic depths. In shallow and middle euphotic depths, clades UC-A, III, and CRD1 were distributed broadly. However, a distinct shift in the horizontal distribution was found at ca. $20^{\circ} \mathrm{N}$. Conversely, clades XVII and CRD2 dominated at deep euphotic depths and constituted a higher proportion than clade II. These niche-partitioning of Synechococcus clades seemed to be related with temperature, nutrient concentration as well as iron concentration.

Key Words: diversity; ecotype; NW Pacific Ocean; Prochlorococcus; pyrosequencing; Synechococcus

\section{INTRODUCTION}

Synechococcus and Prochlorococcus are dominant picocyanobacteria in marine environments, and are known to be one of major primary producers (Li 1994, Liu et al. 1997, Marañón et al. 2001, Teira et al. 2005). However, their biogeographical distributions differ greatly, probably due to physiological and genetic differentiation (Scanlan et al. 2009). Prochlorococcus is predominant in the oligotrophic and tropical open oceans between $40^{\circ} \mathrm{N}$ and $40^{\circ} \mathrm{S}$ (Partensky et al. 1999), while Synechococcus is distributed ubiquitously throughout the world's oceans, ranging from equatorial to sub-polar waters and from coastal to open waters. They are particularly abundant in mesotrophic coastal waters, whereas Prochlorococcus are more abundant in the oligotrophic open oceans. Further, each genus has been known to be composed of diverse clades and / or ecotypes with different physiological and
(P) $\$$ This is an Open Access article distributed under the terms of the Creative Commons Attribution Non-Commercial License (http://creativecommons.org/licenses/by-nc/3.0/) which permits unrestricted non-commercial use, distribution, and reproduction in any medium, provided the original work is properly cited.
Received July 28, 2015, Accepted August 30, 2015

* Corresponding Author

E-mail: jhnoh@kiost.ac.kr

Tel: +82-31-400-6218, Fax: +82-31-408-5934 
ecological traits.

The lineage diversity of picocyanobacteria has been studied using various genetic markers, and this has revealed the existence of very diverse Synechococcus and Prochlorococcus clades or ecotypes (Rocap et al. 2002, Ahlgren and Rocap 2006, Choi and Noh 2009, Martiny et al. 2009, Lavin et al. 2010, West et al. 2011, Huang et al. 2012, Chung et al. 2014). Studies of genetic diversity using 16S-23S internal transcribed spacer (ITS) sequences have shown that Synechococcus and Prochlorococcus can be divided into at least 20 and 10 clades, respectively (Huang et al. 2012, Choi et al. 2013). Furthermore, studies of their spatial distributions have revealed niche partitioning of Prochlorococcus with depth (Moore et al. 1998, West and Scanlan 1999, Johnson et al. 2006) and different biogeographical distribution patterns among Synechococcus clades (Penno et al. 2006, Zwirglmaier et al. 2007, 2008, Tai and Palenik 2009, Mella-Flores et al. 2011, Post et al. 2011, Huang et al. 2012).

Picocyanobacterial diversity can be unveiled using a clone library approach or probe-based molecular techniques, such as dot-blot hybridization and quantitative polymerase chain reaction for specific clades or ecotypes (Ahlgren et al. 2006, Fuller et al. 2006, Zinser et al. 2006, Martiny et al. 2009, Tai and Palenik 2009, Lavin et al. 2010, Rusch et al. 2010, Huang et al. 2012, Sohm et al. 2015). Recently, barcoded amplicon pyrosequencing methods were developed to reveal picocyanobacterial and Synechococcus diversities in marine environments and applied to elucidate the temporal and spatial picocyanobacterial diversity in the marginal seas (Choi et al. 2013, 2014).

The northwestern Pacific Ocean is composed of diverse ecological environments, oligotrophic tropical / subtropical warm pools, oligotrophic Kuroshio Current (KC) and mesotrophic / eutrophic marginal seas. The East China Sea (ECS) is the largest marginal sea affected by oligotrophic pelagic water at the east and by coastal water at the west. Furthermore, the ECS is experiencing most rapid warming (Belkin 2009). The warm pool area has the warmest surface water of the ocean with oligotrophic features (McClain et al. 1999) and is expected to undergo significant changes as consequences of ENSO (El Niño Southern Oscillation) variability (Collins et al. 2010). Therefore, NW Pacific Ocean is an important region to study tele-connections between open oceans and marginal seas and to understand the ecological impacts of changing ocean, such as warming and acidification. Despite the importance, NW Pacific steadily remains one of least explored areas on earth.
To understand distribution and ecological niches of clades / ecotypes of Prochlorococcus and Synechococcus, which are most important picocyanobacteria in marine environments, we investigated 16S-23S ITS sequences of picocyanobacteria by barcoded amplicon pyrosequencing and environmental variables in a transect running from coastal to open waters of the NW Pacific. In addition, diversity of Synechococcus clades was further examined using Synechococcus-specific primers in the oligotrophic waters where their abundance are much less than Prochlorococcus.

\section{MATERIALS AND METHODS}

\section{Study sites and sampling}

Water samples were collected at 16 stations during the POSEIDON (Northwestern Pacific Ocean Study on Environment and Interactions between Deep Ocean and marginal seas) cruise in the northwestern Pacific from May 26 to June 12, 2010 aboard the R/V Onnuri (Fig. 1). Stations (Stns) on lines $\mathrm{F}$ and $\mathrm{P}$ are located in a tropical area affected by the oligotrophic North Equatorial Current (NEC). Stations on line B are located in a subtropical area mainly affected by the KC. Stations on line A and Stn I are located in the ECS, where coastal currents and a branch current (Korea / Tsushima Warm Current) from the KC meet, forming oceanic fronts in the central continental shelf region (Ichikawa and Beardsley 2002). At each station, seawater was sampled from four to six depths between the surface and deep chlorophyll maximum (DCM) depth using Niskin bottles attached to a rosette sampler.

\section{DNA extraction, polymerase chain reaction (PCR) amplification, and pyrosequencing}

The genetic diversity of picocyanobacteria was analyzed in samples collected between the surface and DCM depth. Two liter water samples were passed through a 0.2$\mu \mathrm{m}$ Supor filter (Gelman Sciences, Ann Arbor, MI, USA), and the filters were frozen at $-80^{\circ} \mathrm{C}$ after adding $1 \mathrm{~mL}$ STE buffer (100 mM NaCl, 10 mM Tris-HCl, 1 mM EDTA, pH 8.0). DNA was extracted using the method of Choi et al. (2015).

To elucidate the picocyanobacterial ITS sequence diversity, barcoded amplicon pyrosequencing with GSFLX Titanium (454 Life Sciences, Branford, CT, USA) was carried out. To amplify partial picocyanobacterial ITS sequences, picocyanobacteria-specific ITS-af forward 


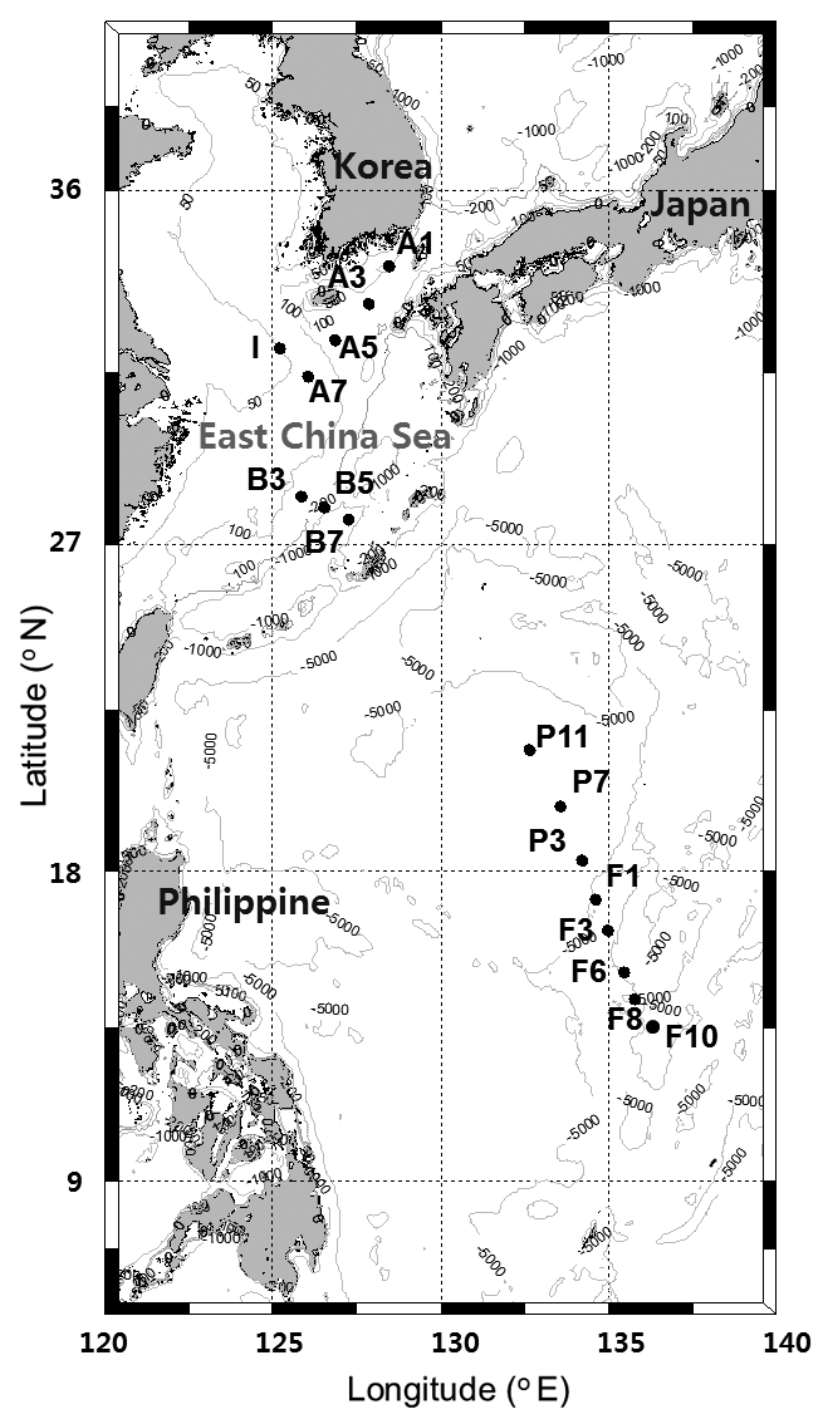

Fig. 1. Sampling stations in the NW Pacific Ocean. Grey contour lines represent water depths.

and ITS-ar reverse primers were used (Choi et al. 2013). The amplification and pyrosequencing was conducted following the procedures shown in Choi et al. (2013). As Synechococcus abundance in the oligotrophic ocean was much less than Prochlorococcus, lineage diversity of Synechococcus could not be resolved in detail from the genetic library targeting picocyanobacteria. Thus, Synechococcus diversity was additionally investigated from the genetic library targeting Synechococcus subcluster-5.1 (SC-5.1). The diversity of Synechococcus SC-5.1 was examined for samples from subtropical and tropical stations between Stns B5 and F10. The PCR amplification using a primer specific to Synechococcus SC-5.1 and pyrosequencing were performed following the protocol in Choi et al. (2014). The sequences obtained using pyrosequencing were submitted to the NCBI sequence read archive (SRA, http://www.ncbi.nlm.nih.gov/Traces/sra; accession number SRA052533.1).

\section{Analyses of pyrosequencing data}

The obtained sequences were analyzed using the mothur program (Schloss et al. 2009) according to the overall procedures presented in Choi et al. (2014). Briefly, raw reads were filtered to remove reads associated with errors by allowing only a perfect match to the barcode and forward primer (in case of picocyanobacterial library, two mismatches to forward primer were allowed) sequences. The allowed number of maximum homopolymers was six. Reads with initial noisy flow (0.5-0.7) before 150 were removed and flows beyond 350 were ignored. The filtered reads were de-noised using the 'shhh.flows' command and the chimeric sequences were removed by 'chimera.perseus' command. The alignment and classification of each read were conducted using the database constructed in the previous study (Choi et al. 2014).

\section{Other analyses}

Synechococcus and Prochlorococcus abundances were determined using a Beckman-Coulter Altra flow cytometer (Campbell and Vaulot 1993). Canonical correspondence analysis (CCA) was performed using Canoco for Windows (ver. 4.51) to understand factors controlling the distribution of the Synechococcus clades. Explanatory variables (nitrate and phosphate concentrations, chl $a$, and Synechococcus abundances), except temperature and salinity, were $\log (\mathrm{n}+1)$ transformed, and response variables (clade \%) were square root transformed before analysis. The CCA model was produced with forward selection via Monte Carlo permutation significance tests. The environmental data used in the CCA analysis was shown in another study (Choi et al. submitted).

\section{RESULTS AND DISCUSSION}

\section{Characteristics of the pyrosequencing runs}

In the analyses of the amplicon library of picocyanobacteria, 49,116 sequences passed our trimming and screening procedures. The number of sequences per sample varied between 97 and 3,290, and averaged 572 . In the Synechococcus SC-5.1 library, 38,540 sequences 


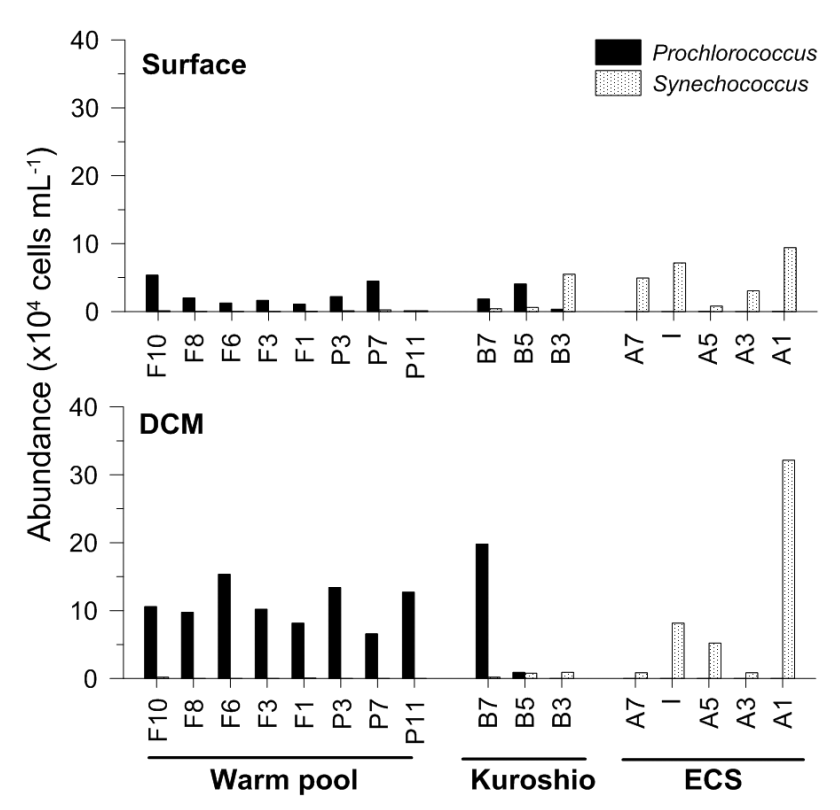

Fig. 2. Abundance distribution of Prochlorococcus and Synechococcus at the surface and deep chlorophyll maximum (DCM) depths. ECS, East China Sea.

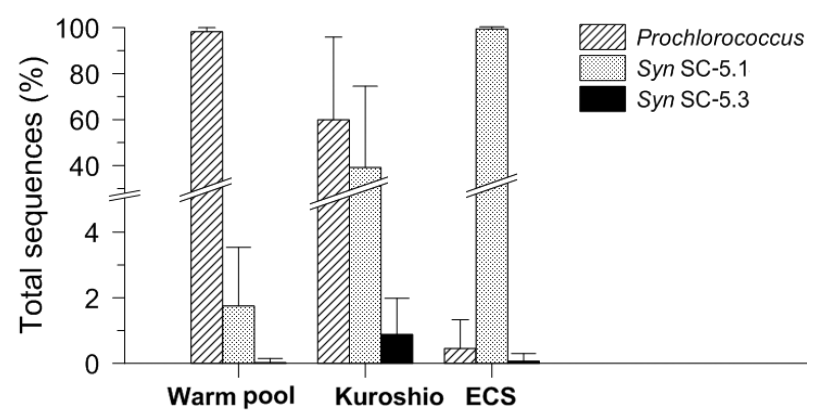

Fig. 3. Percentages of sequences belonging to each picocyanobacterial group among all sequences obtained from an amplicon library of picocyanobacteria in each oceanic area. Sequences belonging to Synechococcus (Syn) subcluster (SC)-5.2 were not found in this study. ECS, East China Sea.

passed our trimming and screening procedures, and were assigned to Synechococcus SC-5.1. The number of sequences per sample for analyses of Synechococcus SC5.1 ranged from 143 to 8,247 . Despite the large variation in read numbers among samples, the clade distribution of the samples with extremely small or large sequence numbers was similar to those in adjacent samples (data not shown). Therefore, these samples were not excluded from this analysis.

\section{Distribution of Synechococcus and Prochlorococ- cus in different oceanic regions}

The abundance of Synechococcus and Prochlorococcus differed among oceanic regions (Fig. 2). Prochlorococcus (0.1-15.4 $\times 10^{4}$ cells $\left.\mathrm{mL}^{-1}\right)$ was much more abundant than Synechococcus $\left(0.01-2.5 \times 10^{3}\right.$ cells $\left.\mathrm{mL}^{-1}\right)$ in oligotrophic tropical waters and had highest abundances around DCM. Synechococcus was more abundant in shallow water. Very few Prochlorococcus was found in the ECS, yet Synechococcus was very abundant $\left(0.8-32.2 \times 10^{4}\right.$ cells $\left.\mathrm{mL}^{-1}\right)$. In the KC region, especially at the boundary of continental shelf, an increase in Synechococcus and a decrease in Prochlorococcus were apparent.

Similarly, the picocyanobacterial amplicon library showed distinct picocyanobacterial diversity among regions (Fig. 3). In tropical warm pool, Prochlorococcus sequences constituted most fractions of picocyanobacterial sequences, whereas Synechococcus sequences were dominant in the ECS. In addition, among the Synechococcus sequences, SC-5.1 was absolutely dominant throughout the study area (Fig. 3). Subcluster-5.3 (SC-5.3) was found significantly (up to $4.1 \%$ ) only in the area near the KC. A recent study in the ECS suggested that SC-5.3 is transported to the ECS via a branch current of the KC (Choi et al. 2013). In addition, SC-5.3 is distributed in subtropical and temperate waters located at the high-latitude boundary of oceanic gyre (Huang et al. 2012). Thus, the geographical niche of Synechococcus SC-5.3 appears to be subtropical oligotrophic waters. In this study, sequences belonging to Synechococcus subcluster-5.2 were not found in most samples. Considering that its dominance in estuarine and coastal waters affected severely by river runoff (Chen et al. 2006, Huang et al. 2012), the absence of this group of Synechococcus seems to be reasonable.

\section{Phylogenetic diversity of picocyanobacteria in the NW Pacific Ocean}

In the warm pool area of the NW Pacific, HLII ecotype Prochlorococcus, adapted to high-light conditions, was exclusively dominant in the upper euphotic zone (Fig. 4). At the lower euphotic depths, HLII ecotypes decreased but low-light adapted LLI ecotype appeared and then increased with depth. The LLIV ecotype was significantly found together with LLI around DCM depth of subtropical waters. However, other ecotypes did not appear significantly in the NW Pacific. The predominance of Prochlorococcus in the oligotrophic warm pool and depth-partitioning of HL and LL ecotypes was consistent 

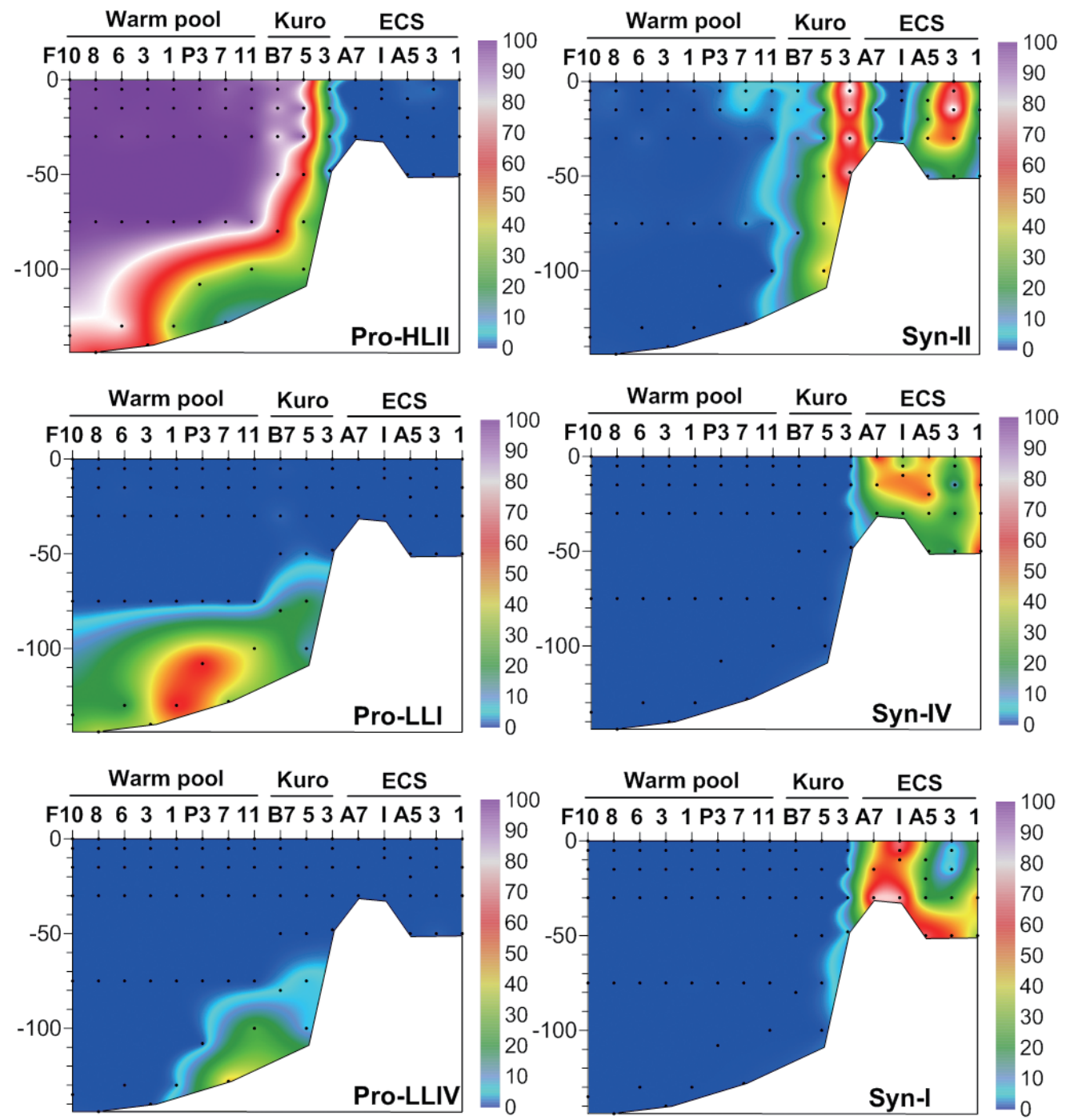

Fig. 4. Contour plots showing the percentages of major picocyanobacterial (Prochlorococcus, Pro; Synechococcus, Syn) lineages as proportions of all picocyanobacterial sequences. Black dots, sampling depths; Kuro, Kuroshio Current; ECS, East China Sea.

with patterns obtained in the various oceanic biomes (Zwirglmaier et al. 2007, 2008).

Similarly, the dominance of Synechococcus clades I, II, and IV in the ECS was also consistent with the previous studies (Choi et al. 2013, 2014). Water temperature, inflow of coastal and / or oligotrophic waters and advection processes have been regarded as important factors in affecting the distribution of picocyanobacterial lineages in the ECS. This wide distribution of clades I and IV in the ECS seems to be related with low temperature less than $21^{\circ} \mathrm{C}$ in the ECS. However, at the stations located around the passage of a branch current of KC, clade II was one of dominant Synechococcus lineages (Fig. 4). As clade II Synechococcus was most dominant picocyanobacteria at the boundary water of continental shelf (Stn. B3), an advective transport by a branch current of KC must be one of important process influencing the Synechococcus lineage distribution in the marginal sea.

\section{Synechococcus diversity in the oligotrophic oceans}

Physiological and genetic diversity and ecological adaptation of Prochlorococcus have been well understood in the previous studies (Johnson et al. 2006, Martiny et al. 2009, Scanlan et al. 2009). On the contrary, despite the higher genetic diversity, ecological niches of Synechococcus clades have not been studied thoroughly as 

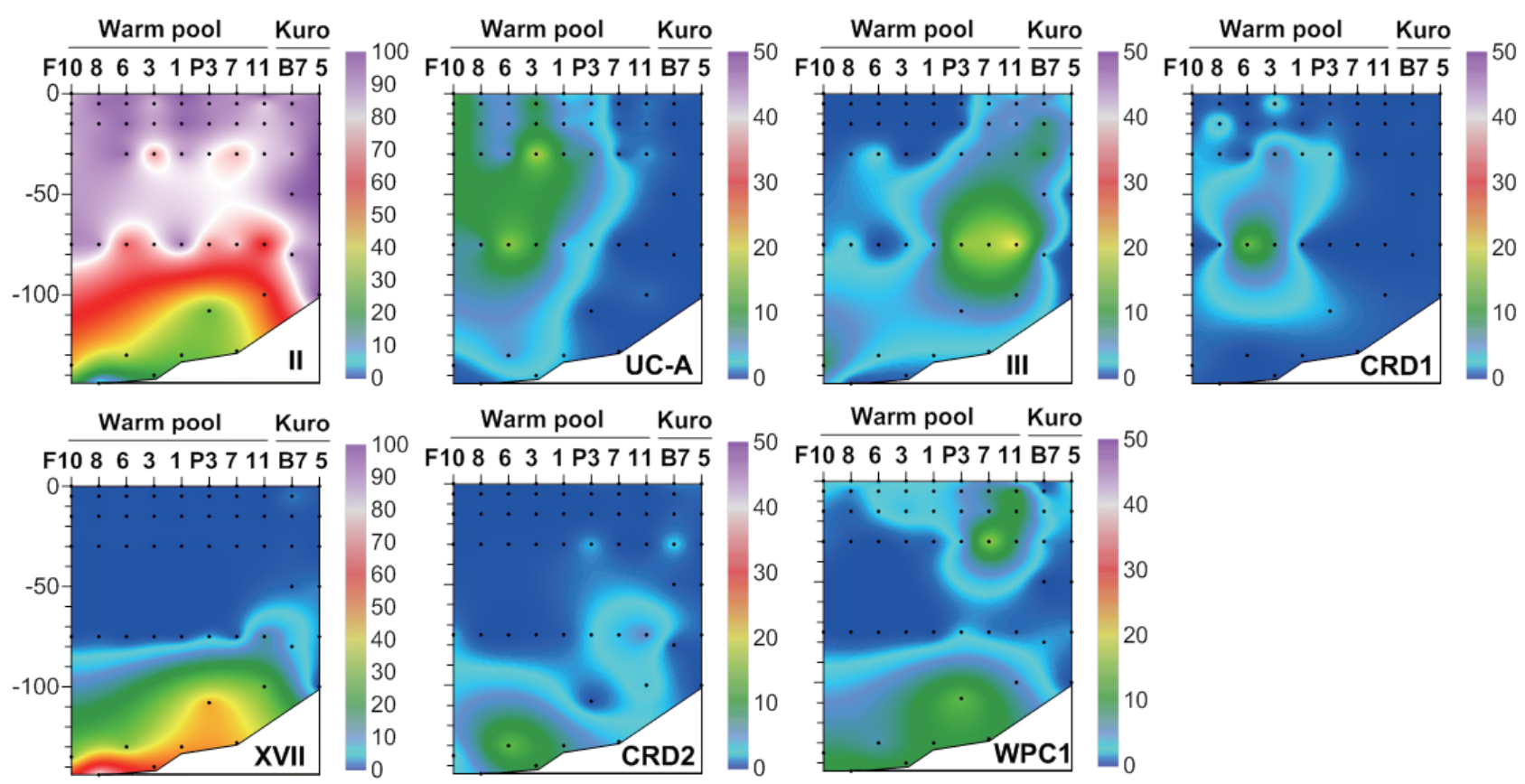

Fig. 5. Contour plots showing the percentages of major Synechococcus clades as proportions to all Synechococcus subcluster-5.1 sequences. Black dots, sampling depths; Kuro, Kuroshio Current.

those of Prochlorococcus. Recently, using the quantitative PCR method, abundance distribution of 10 Synechococcus clades was investigated (Sohm et al. 2015), and they showed that temperature, macronutrients and iron availability are important in clade distribution of Synechococcus. However, the distribution of a half of Synechococcus clades did not incorporated in their study (Fig. 5).

Fifteen clades belonging to Synechococcus SC-5.1 were retrieved in this study (Appendix 1). In warm pool area, seven clades (II, III, XVII, WPC1, UC-A, CRD1, and CRD2) were predominant with proportions of more than $10 \%$ at least one sample among Synechococcus SC-5.1. However, other clades were either found as a minority or not detected. Among the clades found in the ECS, clades I and IV are known to be dominant Synechococcus clades on a global scale (Zwirglmaier et al. 2008, Huang et al. 2012), and considered coastal and cold-adapted Synechococcus (Zwirglmaier et al. 2007, Tai and Palenik 2009, Choi et al. 2013). Considering the ecological traits of these Synechococcus, the insignificant detection of these clades in oligotrophic tropical waters seems to be reasonable.

The distributions of clades V and VI have not been studied intensively due to methodological limitations. Most studies of the distribution of Synechococcus clades have been conducted using a dot-blot hybridization approach (Fuller et al. 2006, Zwirglmaier et al. 2007, 2008). However, the oligonucleotide probe sequence for clade $\mathrm{V}$
/ VI / VII does not separate each clade (Fuller et al. 2003). In the present study, sequences belonging to clades $V$ and VI were nearly not found. Additionally, these sequences have not been retrieved in other tropical / subtropical ocean sites (Huang et al. 2012). However, even though not a dominant clade, clade VII was also found in this study (up to $4 \%$ of Synechococcus SC-5.1), as well as in other studies of the oligotrophic equatorial Pacific and northern Atlantic Oceans (e.g., up to $25 \%$ of total cyanobacteria) (Huang et al. 2012). These data lead to the hypothesis that most Synechococcus previously considered, clade V / VI / VII, in open oceans (Zwirglmaier et al. 2007, 2008) might all belong to clade VII, and further that the preferred habitats of clades V and VI might not be oligotrophic oceans.

For Prochlorococcus, niche partitioning along depth or light intensity gradients has been studied in detail (West and Scanlan 1999, Johnson et al. 2006, Martiny et al. 2009, Lavin et al. 2010), while depth-partitioning of Synechococcus clades has not been examined as thoroughly. In oligotrophic open oceans, euphotic zones are relatively deep, and vertical mixing within the euphotic zone is not active due to thermal stratification. Therefore, oligotrophic open oceans are a good environment for understanding the vertical distribution of Synechococcus lineages. In shallow and mid-euphotic depths, clade II predominated in both tropical and subtropical waters (Fig. 5). Following 
clade II, clades UC-A, III, and CRD1 were the next most dominant clades, but had different latitudinal distributions (Fig. 5). Interestingly, the Synechococcus clade UC-A had a similar depth distribution pattern to clade II in a broad range of shallow euphotic zones, but was limited to low latitudes below $20^{\circ} \mathrm{N}$. Conversely, clade III constituted a higher proportion at latitudes above $20^{\circ} \mathrm{N}$. Therefore, clades III and UC-A showed a distinct latitudinal distribution. However, nutrients (nitrate and phosphate) did not differentiate between the two regions (Choi et al. submitted) despite the well known information on the adaptation of clade III to phosphorus (P)-limited environments (Mella-Flores et al. 2011). More research must be done to determine if other factors, such as trace elements, viral infection, or grazing might be important in the niche-partitioning and spatial variations of these Synechococcus clades (Mann et al. 2002, Mann 2003, Mühling et al. 2005, Saito et al. 2005, Twining et al. 2010, Apple et al. 2011).

Clade CRD1, first identified as a dominant Synechococcus in the Costa Rica upwelling dome (Saito et al. 2005), had a distribution similar to that of UC-A (Fig. 5) in the present study. Recently, clade CRD1 was reported to have a prevailing distribution in tropical regions with low iron availability (Sohm et al. 2015). Actually, dissolved iron concentrations at the low latitude below $20^{\circ} \mathrm{N}$ were estimated to be lower than those at higher latitude (Moore et al. 2002). Thus, latitudinal partitioning of Synechococcus clades around $20^{\circ} \mathrm{N}$ might be related to the distribution of micronutrients including trace elements.

Conversely, clades XVII and CRD2 had relatively high proportions at deeper euphotic zone (Fig. 5), suggesting their adaptation to relatively low temperature and low light ( $<3 \%$ of surface irradiance) or relatively high nutrient conditions. However, their niche was restricted to tropical waters. In the South China Sea, they were found only at mid-euphotic depths (Huang et al. 2012). However, their appearance in the surface waters of the equatorial Pacific Ocean (Huang et al. 2012) suggested that the distribution of clade XVII is not governed by light intensity only.

By definition, the deep euphotic zone is characterized by low light intensity, and also usually has relatively high nutrients and low temperatures compared to surface water. Light intensity plays an important role in discriminating the ecotypes of Prochlorococcus (Moore et al. 1998, West and Scanlan 1999). Furthermore, the different Synechococcus clade distributions along temperature gradients and different genetic compositions related to nutrient utilization among clades have been well studied (Dufresne et al. 2008, Zwirglmaier et al. 2008, Scanlan et

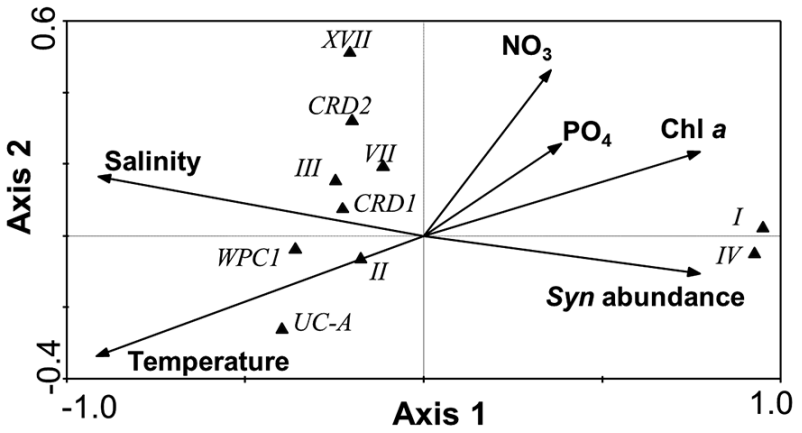

Fig. 6. Canonical correspondence analysis ordination plot showing the relationships between major Synechococcus (Syn) lineages and environmental parameters.

al. 2009). CCA was used to analyze the factors that might explain the spatial distribution of Synechococcus clades in marine environments (Fig. 6). As expected, six explanatory variables (temperature, salinity, nitrate, phosphate, chl $a$, and Synechococcus abundance) were statistically significant by Monte-Carlo permutation tests. Synechococcus clades were divided largely into two groups. Clades I and IV located on right side of the axis 2, indicating that they prefer low temperature and salinity, and high nutrient conditions. Conversely, other clades located on left side of the axis 2 and showed a vertically wide distribution (Fig. 6). As axis 2 correlated well with nutrient concentrations, nutrient supply through nutricline below the euphotic depth might play an important role in determining distribution of Synechococcus clades in oligotrophic waters of the NW Pacific Ocean.

\section{CONCLUSION}

Distribution of picocyanobacterial ecotypes / clades could be clearly differentiated among regions in the NW Pacific Ocean. Prochlorococcus HLII ecotypes were most dominant in the upper euphotic depths of the oligotrophic warm pool, and Prochlorococcus LLI and LLIV ecotypes substituted HLII ecotype at lower euphotic depths. On the contrary, cold-adapted Synechococcus clades I and IV were most dominant in the shelf waters of the ECS. Thus, relative distribution of Prochlorococcus and Synechococcus lineages was generally similar to those of other oceanic regions.

Using a Synechococcus SC-5.1 specific primer and the pyrosequencing method, in-depth distribution of Synechococcus lineages was elucidated in an oligotrophic tropical ocean. While clade II Synechococcus dominated, many other diverse Synechococcus clades were found. 
Furthermore, depth- and latitudinal partitioning of the clades were evident. The depth-partitioning among Synechococcus clades is partly explained by temperature and nutrient levels. In addition, a restricted distribution of clades CRD1 and CRD2 to low-latitude tropical waters suggested that iron concentrations might be another important factor partitioning niches of Synechococcus clades. To better understand the ecological niches of Synechococcus clades, it will be necessary to investigate their diversity in other oceanic environments and in parallel, examine physiological responses and competition along environmental gradients using culture isolates.

\section{ACKNOWLEDGEMENTS}

This study was supported by research programs (PE99319, PM58670) of the Korea Institute of Ocean Science and Technology (KIOST) and the Ministry of Oceans and Fisheries (MOF) of Korea.

\section{REFERENCES}

Ahlgren, N. A. \& Rocap, G. 2006. Culture isolation and culture-independent clone libraries reveal new marine Synechococcus ecotypes with distinctive light and N physiologies. Appl. Environ. Microbiol. 72:7193-7204.

Ahlgren, N. A., Rocap, G. \& Chisholm, S. W. 2006. Measurement of Prochlorococcus ecotypes using real-time polymerase chain reaction reveals different abundances of genotypes with similar light physiologies. Environ. Microbiol. 8:441-454.

Apple, J. K., Strom, S. L., Palenik, B. \& Brahamsha, B. 2011. Variability in protist grazing and growth on different marine Synechococcus isolates. Appl. Environ. Microbiol. 77:3074-3084.

Belkin, I. M. 2009. Rapid warming of large marine ecosystems. Prog. Oceanogr. 81:207-213.

Campbell, L. \& Vaulot, D. 1993. Photosynthetic picoplankton community structure in the subtropical North Pacific Ocean near Hawaii (Station Aloha). Deep-Sea Res. Part I Oceanogr. Res. Pap. 40:2043-2060.

Chen, F., Wang, K., Kan, J., Suzuki, M. T. \& Wommack, K. E. 2006. Diverse and unique picocyanobacteria in Chesapeake Bay, revealed by $16 \mathrm{~S}-23 \mathrm{~S}$ rRNA internal transcribed spacer sequences. Appl. Environ. Microbiol. 72:2239-2243.

Choi, D. H. \& Noh, J. H. 2009. Phylogenetic diversity of Synechococcus strains isolated from the East China Sea and the East Sea. FEMS Microbiol. Ecol. 69:439-448.

Choi, D. H., Noh, J. H. \& Lee, J. -H. 2014. Application of pyrosequencing method for investigating the diversity of Synechococcus subcluster 5.1 in open ocean. Microbes Environ. 29:17-22.

Choi, D. H., Noh, J. H. \& Shim, J. 2013. Seasonal changes in picocyanobacterial diversity as revealed by pyrosequencing in temperate waters of the East China Sea and the East Sea. Aquat. Microb. Ecol. 71:75-90.

Choi, D. H., Park, K. -T., An, S. M., Lee, K., Cho, J. C., Lee, J. H., Kim, D., Jeon, D. \& Noh, J. H. 2015. Pyrosequencing revealed SAR116 clade as dominant dddP-containing bacteria in oligotrophic NW Pacific Ocean. PLoS One 10:e0116271.

Chung, C. -C., Huang, C. -Y., Gong, G. -C. \& Lin, Y. -C. 2014. Influence of the Changjiang River flood on Synechococcus ecology in the surface waters of the East China Sea. Microb. Ecol. 67:273-285.

Collins, M., An, S. -I., Cai, W., Ganachaud, A., Guilyardi, E., Jin, F. -F., Jochum, M., Lengaigne, M., Power, S., Timmermann, A., Vecchi, G. \& Wittenberg, A. 2010. The impact of global warming on the tropical Pacific Ocean and El Niño. Nat. Geosci. 3:391-397.

Dufresne, A., Ostrowski, M., Scanlan, D. J., Garczarek, L., Mazard, S., Palenik, B. P., Paulsen, I. T., de Marsa, N. T., Wincker, P., Dossat, C., Ferriera, S., Johnson, J., Post, A. F., Hess, W. R. \& Partensky, F. 2008. Unraveling the genomic mosaic of a ubiquitous genus of marine cyanobacteria. Genome Biol. 9:R90.

Fuller, N. J., Marie, D., Partensky, F., Vaulot, D., Post, A. F. \& Scanlan, D. J. 2003. Clade-specific 16S ribosomal DNA oligonucleotides reveal the predominance of a single marine Synechococcus clade throughout a stratified water column in the Red Sea. Appl. Environ. Microbiol. 69:2430-2443.

Fuller, N. J., Tarran, G. A., Yallop, M., Orcutt, K. M. \& Scanlan, D. J. 2006. Molecular analysis of picocyanobacterial community structure along an Arabian Sea transect reveals distinct spatial separation of lineages. Limnol. Oceanogr. 51:2515-2526.

Huang, S., Wilhelm, S. W., Harvey, H. R., Taylor, K., Jiao, N. \& Chen, F. 2012. Novel lineages of Prochlorococcus and Synechococcus in the global oceans. ISME J. 6:285-297.

Ichikawa, H. \& Beardsley, R. C. 2002. The current system in the Yellow and East China Seas. J. Oceanogr. 58:77-92.

Johnson, Z. I., Zinser, E. R., Coe, A., McNulty, N. P., Woodward, E. M. S. \& Chisholm, S. W. 2006. Niche partitioning among Prochlorococcus ecotypes along ocean-scale environmental gradients. Science 311:1737-1740.

Lavin, P., González, B., Santibáñez, J. F., Scanlan, D. J. \& Ulloa, 
O. 2010. Novel lineages of Prochlorococcus thrive within the oxygen minimum zone of the eastern tropical South Pacific. Environ. Microbiol. Rep. 2:728-738.

Li, W. K. W. 1994. Primary production of prochlorophytes, cyanobacteria, and eucaryotic ultraphytoplankton: measurements from flow cytometric sorting. Limnol. Oceanogr. 39:169-175.

Liu, H., Nolla, H. A. \& Campbell, L. 1997. Prochlorococcus growth rate and contribution to primary production in the equatorial and subtropical North Pacific Ocean. Aquat. Microb. Ecol. 12:39-47.

Mann, E. L., Ahlgren, N., Moffett, J. W. \& Chisholm, S. W. 2002. Copper toxicity and cyanobacteria ecology in the Sargasso Sea. Limnol. Oceanogr. 47:976-988.

Mann, N. H. 2003. Phages of the marine cyanobacterial picophytoplankton. FEMS Microbiol. Rev. 27:17-34.

Marañón, E., Holligan, P. M., Barciela, R., González, N., Mouriño, B., Pazó, M. J. \& Varela, M. 2001. Patterns of phytoplankton size structure and productivity in contrasting open-ocean environments. Mar. Ecol. Prog. Ser. 216:43-56.

Martiny, A. C., Tai, A. P. K., Veneziano, D., Primeau, F. \& Chisholm, S. W. 2009. Taxonomic resolution, ecotypes and the biogeography of Prochlorococcus. Environ. Microbiol. 11:823-832.

McClain, C. R., Murtugudde, R. \& Signorini, S. 1999. A simulation of biological processes in the equatorial Pacific Warm Pool at $165^{\circ}$ E. J. Geophys. Res. Oceans 104:1830518322.

Mella-Flores, D., Mazard, S., Humily, F., Partensky, F., Mahe, F., Bariat, L., Courties, C., Marie, D., Ras, J., Mauriac, R., Jeanthon, C., Bendif, E. M., Ostrowski, M., Scanlan, D. J. \& Garezarek, L. 2011. Is the distribution of Prochlorococcus and Synechococcus ecotypes in the Mediterranean Sea affected by global warming? Biogeosciences 8:27852804.

Moore, J. K., Doney, S. C., Glover, D. M. \& Fung, I. Y. 2002. Iron cycling and nutrient-limitation patterns in surface waters of the World Ocean. Deep-Sea Res. Part II Top. Stud. Oceanogr. 49:463-507.

Moore, L. R., Rocap, G. \& Chisholm, S. W. 1998. Physiology and molecular phylogeny of coexisting Prochlorococcus ecotypes. Nature 393:464-467.

Mühling, M., Fuller, N. J., Millard, A., Somerfield, P. J., Marie, D., Wilson, W. H., Scanlan, D. J., Post, A. F., Joint, I. \& Mann, N. H. 2005. Genetic diversity of marine Synechococcus and co-occurring cyanophage communities: evidence for viral control of phytoplankton. Environ. Microbiol. 7:499-508.

Partensky, F., Hess, W. R. \& Vaulot, D. 1999. Prochlorococcus, a marine photosynthetic prokaryote of global significance. Microbiol. Mol. Biol. Rev. 63:106-127.

Penno, S., Lindell, D. \& Post, A. F. 2006. Diversity of Synechococcus and Prochlorococcus populations determined from DNA sequences of the N-regulatory gene ntcA. Environ. Microbiol. 8:1200-1211.

Post, A. F., Penno, S., Zandbank, K., Paytan, A., Huse, S. M. \& Welch, D. M. 2011. Long term seasonal dynamics of Synechococcus population structure in the Gulf of Aqaba, Northern Red Sea. Front. Microbiol. 2:131.

Rocap, G., Distel, D. L., Waterbury, J. B. \& Chisholm, S. W. 2002. Resolution of Prochlorococcus and Synechococcus ecotypes by using 16S-23S ribosomal DNA internal transcribed spacer sequences. Appl. Environ. Microbiol. 68:1180-1191.

Rusch, D. B., Martiny, A. C., Dupont, C. L., Halpern, A. L. \& Venter, J. C. 2010. Characterization of Prochlorococcus clades from iron-depleted oceanic regions. Proc. Natl. Acad. Sci. U. S. A. 107:16184-16189.

Saito, M. A., Rocap, G. \& Moffett, J. W. 2005. Production of cobalt binding ligands in a Synechococcus feature at the Costa Rica upwelling dome. Limnol. Oceanogr. 50:279290.

Scanlan, D. J., Ostrowski, M., Mazard, S., Dufresne, A., Garczarek, L., Hess, W. R., Post, A. F., Hagemann, M., Paulsen, I. \& Partensky, F. 2009. Ecological genomics of marine picocyanobacteria. Microbiol. Mol. Biol. Rev. 73:249-299.

Schloss, P. D., Westcott, S. L., Ryabin, T., Hall, J. R., Hartmann, M., Hollister, E. B., Lesniewski, R. A., Oakley, B. B., Parks, D. H., Robinson, C. J., Sahl, J. W., Stres, B., Thallinger, G. G., Van Horn, D. J. \& Weber, C. F. 2009. Introducing mothur: open-source, platform-independent, community-supported software for describing and comparing microbial communities. Appl. Environ. Microbiol. 75:7537-7541.

Sohm, J. A., Ahlgren, N. A., Thomson, Z. J., Williams, C., Moffett, J. W., Saito, M. A., Webb, E. A. \& Rocap, G. 2015. Co-occurring Synechococcus ecotypes occupy four major oceanic regimes defined by temperature, macronutrients and iron. ISME J. Advanced online publication. http://dx.doi.org/10.1038/ismej.2015.115.

Tai, V. \& Palenik, B. 2009. Temporal variation of Synechococcus clades at a coastal Pacific Ocean monitoring site. ISME J. 3:903-915.

Teira, E., Mouriño, B., Marañón, E., Pérez, V., Pazó, M. J., Serret, P., de Armas, D., Escánez, J., Woodward, E. M. S. \& Fernández, E. 2005. Variability of chlorophyll and primary production in the Eastern North Atlantic Subtropical Gyre: potential factors affecting phytoplankton activity. Deep-Sea Res. Part I Oceanogr. Res. Pap. 52:569-588. 
Twining, B. S., Nuñez-Milland, D., Vogt, S., Johnson, R. S. \& Sedwick, P. N. 2010. Variations in Synechococcus cell quotas of phosphorus, sulfur, manganese, iron, nickel, and zinc within mesoscale eddies in the Sargasso Sea. Limnol. Oceanogr. 55:492-506.

West, N. J., Lebaron, P., Strutton, P. G. \& Suzuki, M. T. 2011. A novel clade of Prochlorococcus found in high nutrient low chlorophyll waters in the South and Equatorial Pacific Ocean. ISME J. 5:933-944.

West, N. J. \& Scanlan, D. J. 1999. Niche-partitioning of Prochlorococcus populations in a stratified water column in the eastern North Atlantic Ocean. Appl. Environ. Microbiol. 65:2585-2591.

Zinser, E. R., Coe, A., Johnson, Z. I., Martiny, A. C., Fuller, N.
J., Scanlan, D. J. \& Chisholm, S. W. 2006. Prochlorococcus ecotype abundances in the North Atlantic Ocean as revealed by an improved quantitative PCR method. Appl. Environ. Microbiol. 72:723-732.

Zwirglmaier, K., Heywood, J. L., Chamberlain, K., Woodward, E. M. S., Zubkov, M. V. \& Scanlan, D. J. 2007. Basin-scale distribution patterns of picocyanobacterial lineages in the Atlantic Ocean. Environ. Microbiol. 9:1278-1290.

Zwirglmaier, K., Jardillier, L., Ostrowski, M., Mazard, S., Garczarek, L., Vaulot, D., Not, F., Massana, R., Ulloa, O. \& Scanlan, D. J. 2008. Global phylogeography of marine Synechococcus and Prochlorococcus reveals a distinct partitioning of lineages among oceanic biomes. Environ. Microbiol. 10:147-161.

Appndix 1. Percentages (mean \pm 1 standard deviation, ranges) of Synechococcus lineages found in this study as proportions of all sequences belonging to Synechococcus subcluster-5.1 sequences

\begin{tabular}{|c|c|c|c|c|c|}
\hline \multirow{2}{*}{$\begin{array}{l}\text { Clades } \\
\text { I }\end{array}$} & \multicolumn{2}{|c|}{ East China Sea } & Kuroshio & \multicolumn{2}{|c|}{ Warm pool } \\
\hline & $37.95 \pm 24.45$ & $(0-77.1)$ & $0.72 \pm 1.55(0-5.0)$ & $0 \pm 0.01$ & $(0-0.09)$ \\
\hline II & $24.97 \pm 30.49$ & $(0-94.4)$ & $90.97 \pm 4.58 \quad(81.9-97.1)$ & $77.85 \pm 20.73$ & $(2.6-94.7)$ \\
\hline III & $0.17 \pm 0.64$ & $(0-3)$ & $2.65 \pm 3.02(0-8.7)$ & $3.27 \pm 4.83$ & $(0-20.7)$ \\
\hline IV & $36.07 \pm 18.54$ & $(0-63.4)$ & $0.2 \pm 0.48 \quad(0-1.5)$ & $0 \pm 0$ & $(0-1.3)$ \\
\hline VI & $0 \pm 0$ & $(0-0)$ & $0.02 \pm 0.06(0-0.3)$ & $0 \pm 0$ & $(0-0)$ \\
\hline VII & $0.18 \pm 0.42$ & $(0-1.2)$ & $0.62 \pm 0.98(0-4.0)$ & $0.39 \pm 0.87$ & $(0-4.0)$ \\
\hline IX & $0.02 \pm 0.08$ & $(0-0.4)$ & $0.37 \pm 0.67 \quad(0-2.3)$ & $0 \pm 0.01$ & $(0-0.1)$ \\
\hline XVI & $0.04 \pm 0.1$ & $(0-0.4)$ & $0.11 \pm 0.27(0-1)$ & $0 \pm 0$ & $(0-0)$ \\
\hline XVII & $0.21 \pm 0.49$ & $(0-2)$ & $1.7 \pm 1.67 \quad(0-7.0)$ & $5.84 \pm 15.83$ & $(0-81.3)$ \\
\hline CB1 & $0 \pm 0$ & $(0-0)$ & $0 \pm 0 \quad(0-0)$ & $0 \pm 0.03$ & $(0-0.2)$ \\
\hline CRD1 & $0.36 \pm 1.09$ & $(0-5)$ & $0.39 \pm 1.11(0-4.6)$ & $1.20 \pm 2.54$ & $(0-14.7)$ \\
\hline CRD2 & $0.02 \pm 0.08$ & $(0-0.4)$ & $1.02 \pm 1.04(0-4.0)$ & $1.05 \pm 2.44$ & $(0-13.9)$ \\
\hline WPC1 & $0 \pm 0$ & $(0-0)$ & $1.02 \pm 1.08(0-3.3)$ & $3.91 \pm 3.91$ & $(0-16.8)$ \\
\hline UC-A & $0.02 \pm 0.08$ & $(0-0.7)$ & $0.21 \pm 0.31 \quad(0-1.0)$ & $5.1 \pm 4.47$ & $(0-18.5)$ \\
\hline MS2 & $0 \pm 0$ & $(0-0)$ & $0 \pm 0$ & $0 \pm 0.03$ & $(0-0.17)$ \\
\hline
\end{tabular}

